\title{
Globe
}

Revue internationale d'études québécoises

\section{Un état des lieux}

\section{Hans-Jürgen Lüsebrink}

Volume 7, numéro 2, 2004

Américanités francophones. Ancrages médiatiques, mises en perspective historiques et comparatistes

URI : https://id.erudit.org/iderudit/1000858ar

DOI : https://doi.org/10.7202/1000858ar

Aller au sommaire du numéro

\section{Éditeur(s)}

Globe, Revue internationale d'études québécoises

ISSN

1481-5869 (imprimé)

1923-8231 (numérique)

Découvrir la revue

Citer ce document

Lüsebrink, H.-J. (2004). Un état des lieux. Globe, 7(2), 11-20.

https://doi.org/10.7202/1000858ar d'utilisation que vous pouvez consulter en ligne.

https://apropos.erudit.org/fr/usagers/politique-dutilisation/ 


\section{Introduction Un état des lieux}

\section{Hans-Jürgen Lüsebrink Université de la Sarre (Allemagne)}

L'américanité constitue, depuis plus d'une vingtaine d'années, un des champs de recherche et de discussion de tout premier plan dans la littérature et dans le domaine des lettres et sciences humaines au Québec et, en général, au Canada francophone. Louis Dupont a ainsi pu affirmer en 1995 que ce concept constitue depuis les années 1980 une "référence constante" du discours identitaire québécois : "a constant reference throughout the 1980's, and the phenomenon seems to bave continued into the present decade within intellectual and artistic circles, as well as in popular culture ${ }^{1}$. Ce concept d'“ américanité ", que Dupont traduit par "americanness, in the sense of the continent ${ }^{2}$ ", postule de manière parfois manifestaire, l'appartenance - en l'occurrence, des cultures francophones - au continent américain dans ses dimensions géopolitique et culturelle, c'est-à-dire dans sa géographie particulière, son histoire imprégnée des expériences pluriséculaires de la conquête et de la colonisation, et ses cultures qui sont toutes marquées par une immigration venue d'horizons extrêmement divers. Cette immigration a au surplus mené à des relations interculturelles fort complexes. Le concept d'américanité se trouve ainsi au centre d'une "nouvelle vision - des cultures américaines qui s'est développée au Québec, mais aussi en Acadie, surtout à partir des années 1980. "Le thème de l'américanité (ou de la nord-américanité) ", souligne Gérard Bouchard dans Genèse des nations

1. Louis Dupont, "L'américanitê in Quebec in the 1980s: Political and Cultural Considerations of an Emerging Discours *, The American Review of Canadian Studies, printemps 1995, p. 27.

2. Ibid., p. 27.

Hans-Jürgen Lüsebrink, * Introduction. Un état des lieux *, Globe. Revue internationale d'études québécoises, vol. 7, n 2, 2004. 
et cultures du Nouveau Monde, "a fait alors son entrée dans le discours littéraire et artistique. Le roman a commencé à faire voyager ses héros aux États-Unis, à y situer une partie de ses intrigues. L'Amérique du Sud fit son apparition aussi, projetée dans une nouvelle proximité de tempérament, de culture latine ${ }^{3}$. De nombreux écrivains, artistes et cinéastes québécois et canadiens-français ont fictionnalisé, pendant les deux dernières décennies, cette "nouvelle vision " d'un Québec et d'un Canada francophone profondément ancrés mentalement, culturellement et symboliquement dans le continent américain. Ils ont ainsi manifesté non seulement leur spécifité quant à la culture de la France métropolitaine, mais aussi leur distance par rapport à d'autres cultures dites francophones : prenons par exemple Claude Beausoleil, qui proposa de "dessiner les voix de l'Amérique en français * et de " décrire cette américanité à travers des textes et des ouvrages qui tiennent compte du reférent continental et des origines ${ }^{4}$; les poètes acadiens Herménégilde Chiasson et Raymond LeBlanc, qui soulignèrent la dimension visuelle de la culture américaine, amplifiée par l'impact du cinéma états-unien et de la télévision ${ }^{5}$; ou encore Jacques Poulin (Volkswagen Blues, 1983), Jacques Languirand ( Le Québec et l'américanité ", 1971) et Jacques Godbout (Une bistoire américaine, 1986), dont les œuvres romanesques sont peut-être les expressions littéraires les plus significatives de l'ouverture transcontinentale et américaine des littératures francophones du Canada.

Ce versant littéraire et artistique de l'imaginaire de l'américanité a été analysé dans de nombreuses études universitaires. Un numéro de la revue Tangence (alors nommée Urgences) dirigé par Jean Morency interrogea ainsi en 1991 "la place, dans la littérature québécoise, de cette Amérique imaginaire et fantasmatique qui nous habite bien plus que nous l'habiterons jamais ${ }^{6}$. Le dossier sur "L'Amérique de la littérature

3. Gérard Bouchard, Genèse des nations et cultures du Nouveau Monde, Montréal, Boréal, 2000, p. 161.

4. Claude Beausoleil, "Préface. À propos d'un colloque : entre la théorie et la fiction ", Les cent lignes de notre américanité. Actes du colloque tenu à Moncton du 14 au 16 juin 1984, Moncton, Éditions Perce-Neige, 1984, p. 7.

5. Herménégilde Chiasson, - Il y a cent vingt-cinq lignes *, Les cent lignes de notre américanité, op. cit., p. 13-17; Raymond LeBlanc, "Nos images Kodak ", Les cent lignes de notre américanitê, op. cit., p. 27-31.

6. Jean Morency, "Liminaire ., Urgences, no 34, 1991, p. 6. 
québécoise. de la revue Études françaises élargit le corpus de représentations étudié. Il y inclut notamment le thêâtre et aborde la problématique - toujours peu étudiée - des traductions de textes étatsuniens en France et au Québec et leur impact sur le théâtre francophone contemporain ${ }^{7}$. La même revue consacra en 1992 un numéro à "L'Amérique entre les langues ", qui mettait l'accent sur le multilinguisme fondateur des Amériques et l'espace culturel caribéen, ainsi que sur les transferts culturels entre les différentes sphères linguistiques et culturelles du continent américain et les phénomènes de métissage ou d'hybridation, que le linguiste martiniquais Jean Bernabé proposa de cerner à travers une perspective comparatiste ${ }^{8}$. Jean-François Chassay et Jean Morency ont quant à eux analysé, dans une perspective à la fois comparatiste et interculturelle, l'impact du roman états-unien sur la littérature québécoise et les images de l'Amérique dans le roman québecois contemporain. L'exploration de ce champ d'études se révèle d'une grande richesse et fait ressortir, entre autres, l'influence d'auteurs états-uniens comme Nathaniel Hawthorne, Herman Melville, John Dos Passos, Ernest Hemingway et Washington Irving sur toute une génération d'écrivains québécois contemporains, dont Jacques Poulin, Nicole Brossard, Victor-Lévy Beaulieu, Monique LaRue et Réjean Ducharme9.

7. Voir plus particulièrement dans ce numéro d'Études françaises (vol. 26, $\mathrm{n}^{\circ} 2$, 1990) la bibliographie commentée établie par Benoît Melançon (p. 80-108) et les articles de Lucie Robert (. L'américanité de la dramaturgie québécoise *, p. 61-64), de Diane Pavlovic (" Le théâtre québécois récent et l'américanité •, p. 41-48) et d'Annie Brisset (* La traduction du théâtre américain au Québec *, p. 49-52). Voir aussi, sur la problématique des traductions de la littérature états-unienne au Québec, l'article stimulant et bien documenté de Jean Morency : * Connaissance de la littérature américaine au Québec, de la traduction à l'intégration ", Robert A. Stebbins, Claude Romney et Micheline Ouellet [éd.], Francopbonie et langue dans un monde divers en évolution : contacts interlinguistiques et socioculturels. Actes du dix-neuvième colloque du CEFECO (18-20 octobre 2001), Winnipeg, Presses universitaires de Saint-Boniface, 2003, p. 195-206.

8. Jean Bernabé, "De la négritude à la créolité : éléments pour une approche comparée *, Études françaises, vol. 28, n²-3, automne 1992-hiver 1993, - L'Amérique entre les langues ", p. 23-29.

9. Jean Morency, Le mythe américain dans les fictions d'Amérique. De Washington Irving à Jacques Poulin, Québec, Nuit blanche éditeur, 1994 ; JeanFrançois Chassay, L'ambiguité américaine. Le roman québécois face aux ÉtatsUnis, Montréal, XYZ, coll. - Théorie et littérature *, 1995; Jonathan M. Weiss, -Victor-Lévy Beaulieu : écrivain américain •, Études françaises, vol. $19, \mathrm{n}^{\circ} 1$, 
Pierre Nepveu, enfin, explore dans son ouvrage Intérieurs du Nouveau Monde une toute autre dimension de l'américanité : non pas celle des grands espaces et de l'aventure, dominante dans la fiction romanesque, mais celle, plus attachée aux genres poétiques, d'un " retour chez soi, parfois heureux, souvent terrible ${ }^{10}$ " et basé sur une subjectivité fragile et son intimité. Nepveu met en parallèle des poètes et écrivains états-uniens (tels Nathaniel Hawthorne, Hart Crane et Wallace Stevens), et des écrivains québécois (dont Anne Hébert et Saint-Denys Garneau) pour montrer à la fois leur soubassement américain commun et les spécificités francophones de l'appropriation de l'expérience américaine.

Les travaux d'Yvan Lamonde ont donné une profondeur historique à cette nouvelle vision identitaire québécoise et canadienne-française que reflète la notion d'américanité. Il a en effet montré dans ses recherches que la construction d'une identité américaine des Québécois n'est pas récente. Elle remonte au contraire aux dernières décennies du XviI $^{e}$ siècle, c'est-à-dire au lendemain de la conquête du Canada français par l'Empire Britannique, et prend une tournure particulière avec le mouvement des Patriotes de 1837-1838 et l'émergence du nationalisme québécois suivant la répression de cette révolte. En citant en exergue d'un chapitre de son livre Allégeance et dépendances le patriote Papineau - "il ne s'agit que de savoir que nous vivons en Amérique et de savoir comment on y a vécu "-, Lamonde retrace la généalogie du concept d'américanité et des dispositifs culturels et mentaux que celui-ci reflète. Sa célèbre formule " $Q=(F)+(G B)+(U S A)^{2}$ " résume de manière délibérément schématique et pédagogique les composantes de l'identité québécoise moderne et vise à souligner précisément que

dans l'identité du Québec, la marque de la France devait être ramenée à de nouvelles proportions tout en demeurant la principale; que la Grande-Bretagne a laissé un héritage plus important que celui que les

printemps 1983, p. 41-57; * Image des États-Unis dans le roman québécois moderne ", The American Review of Canadian Studies, vol. 5, $n^{\circ} 2$, automne 1975, p. 82-102.

10. Pierre Nepveu, Intêrieurs du Nouveau Monde. Essais sur les littératures du Québec et des Amériques, Montréal, Boréal, coll. • Papiers collés *, 1998, p. 26. 
" conquis - québécois étaient capables d'admettre; que l'influence étatsunienne, ramifiante dans l'économie, le syndicalisme, le loisir et la culture matérielle, était intensément vécue sans affluer au niveau de la conscience de l'aveu ; que les positions du Vatican à l'égard du Canada français et du Québec s'étaient révélées contraires aux attentes et aux idées reçues ${ }^{11}$.

Son livre Ni avec eux ni sans eux. Le Québec et les États-Unis, dont le titre est devenu quasi emblématique pour désigner toute l'ambiguité des relations entre les deux pays, retrace leur complexité sur une période allant des premières décennies de la colonisation du Québec par l'Empire Britannique, marquées par la " construction d'une identité américaine ", jusqu'aux années 1990, caractérisées selon l'auteur par un "Québec presqu'Amérique ". Le livre s'achève sur l'esquisse d'une double trajectoire de l'expérience et de l'appropriation de l'américanité, s'appuyant sur le sens à la fois anthropologique (valeurs véhiculées par les États-Unis), matériel (culture de consommation) et intellectuel (impact de la culture intellectuelle états-unienne) du terme "culture ": celle, d'une part, d'un parcours collectif marqué par un ancrage social, économique et culturel du Québec dans un continent américain où les États-Unis, qui occupent une place toujours prédominante, se voient rattrapés par les échanges entre le Québec et l'Amérique latine - ancrage de plus en plus ample et complexe; et celle, d'autre part, d'un parcours personnel où Yvan Lamonde évoque sa " propre expérience des États-Unis et des Amériques ", partant du constat que "l'enfance de mon américanité est aussi l'américanité de mon enfance et de mon adolescence ${ }^{12}{ }_{n}$.

Yvan Lamonde et des chercheurs comme Gérard Bouchard, Esther Trépanier, Florian Sauvageau, Claude Savary, Bernard Lemelin et Donald Cuccioletta ${ }^{13}$ montrent, à travers la perspective socio-historique qu'ils

11. Yvan Lamonde, Allégeances et dépendances. L'bistoire d'une ambivalence identitaire, Québec, Nota bene, 2000, p. 29-30.

12. lbid., p. 93-94.

13. Gérard Bouchard, op. cit. ; Florian Sauvageau léd.], Variations surl'influence culturelle américaine, Sainte-Foy, Presses de l'Université Laval, 1999; Donald Cuccioletta [éd.], L'Amérique et les Amériques, Québec, Éditions de l'IRQRC, 2001 ; Claude Savary [éd.], Les rapports culturels entre le Québec et les États-Unis, 


\section{REVUE INTERNATIONALE D'ÉTUDES QUÉBÉCOISES}

développent, que l'américanité est le résultat, sur les plans social et socio-culturel, des processus d'américanisation. Ceux-ci se sont intensifiés dans le contexte de la mondialisation contemporaine, mais ont marqué toute l'introduction de la modernité industrielle, économique et médiatique au Québec, depuis les dernières décennies du Xxx siècle. Les transferts économiques et culturels entre les États-Unis et le Québec, pour lesquels les Franco-Américains constituaient d'importants intermédiaires culturels ${ }^{14}$, ont en effet profondément marqué et transformé la société canadienne-française dans toutes les formes de sa culture matérielle : des produits de consommation à la publicité, en passant par l'architecture, l'aménagement des villes et l'esthétique des intérieurs de bureaux. La culture intellectuelle a été marquée par l'influence étatsunienne surtout à travers la culture médiatique - radio, presse moderne, télévision, cinéma, vidéo, Internet -, dont l'introduction, à partir du début du $\mathrm{xx}^{\mathrm{e}}$ siècle, s'est effectuée largement depuis les États-Unis et beaucoup moins - sauf dans le domaine de l'imprimé, en particulier de la presse périodique - depuis la France ou l'Europe en général.

La prise de distance à la fois la plus poussée et la plus controversée par rapport au concept d'américanité et aux recherches qui y sont liées a sans doute été formulée par le sociologue Joseph Yvon Thériault, dans son livre Critique de l'américanité. Mémoire et démocratie au Québec (2002). Aboutissant à la thèse que "la simple existence d'un peuple francophone en Amérique du Nord est en soi une affirmation substantielle, l'affirmation d'une altérité au cœeur de l'Amérique, le refus de l'américanité ${ }^{15}$ ", Thériault critique l'introduction de l'américanité comme composante de l'identité canadienne-française et québécoise. Discutable parce que basé sur une mise en parallèle trop schématique entre amé-

ricanité, américanisation, modernité et normalisation, réduisant

Québec, Institut québécois de recherche sur la culture, 1984 ; Bernard Lemelin, - Au-delà de l'américanisation culturelle: les influences politiques et économiques des États-Unis sur le Canada et le Québec, 1867-1988 *, Florian Sauvageau [éd.], op. cit., p. 101-117.

14. Voir Yvan Lamonde, Ni avec eux ni sans eux: le Québec et les États-Unis, Québec, Nuit blanche éditeur, 1996.

15. Joseph Yvon Thériault, Critique de l'américanité. Mémoire et démocratie au Québec, Montréal, Québec Amérique, 2002, p. 317. 
l'américanité aux seuls rapports avec les États-Unis, l'ouvrage a suscité des débats et des controverses qui ont le mérite d'avoir clairement dégagé la configuration particulière et les enjeux des réflexions et recherches sur l'américanité au Québec. Il a, d'abord, permis de repenser, documents d'archives et données socio-culturelles à l'appui, l'identité du Québec, dont les rapports avec d'autres sociétés et cultures, en particulier, mais pas exclusivement, avec celle des États-Unis, constituent sans conteste une des composantes ${ }^{16}$. En même temps, la réflexion sur l'américanité montre que celle-ci est à la fois éthique, culturelle et scientifique, analytique et normative, en tendant à effacer les lignes de partage généralement beaucoup plus étanches entre ces différents discours. Yvan Lamonde, Gérard Bouchard et Jean Morency ont souligné la nécessité de recherches comparatistes et interculturelles afin de faire avancer la réflexion, recherches devant porter entre autres sur les littératures coloniales américaines et québécoise, les " imaginaires " et "itinéraires socio-politiques des collectivités neuves ${ }^{17}$, ou encore les transferts littéraires, journalistiques et artistiques entre le Canada francophone et les autres sociétés et cultures du continent américain ${ }^{18}$.

\section{Mises en perspective}

Le présent dossier, constitué majoritairement par des chercheurs européens, vise à la fois à renouer avec les perspectives de recherche esquissées et à explorer quelques nouvelles pistes dans un champ loin

16. Voir la critique du livre de Thériault par Yvan Lamonde dans le Bulletin d'bistoire politique, vol. $11, \mathrm{n}^{\circ} 2$, hiver 2002 , p. 181.

17. Voir Gérard Bouchard, - L'histoire comparée des collectivités neuves ou cultures fondatrices ", Genèse des nations et cultures, op. cit., p. 17.

18. Voir les travaux en cours de Jean Morency sur les transferts littéraires entre les États-Unis et le Québec avant 1960. Voir aussi Florian Sauvageau, op. cit.; Patrick Imbert, Trajectoires culturelles transaméricaines. Médias, publicité, littérature et mondialisation, Ottawa, Presses de l'Université d'Ottawa, coll. * Transferts culturels/Cultural Transfers *, 2004, vol. 1 ; Daniel Castillo-Durante et Patrick Imbert [éd.], L'interculturel au cœur des Amériques, New York/Ottawa/Toronto, Legas, 2003; Yvan Lamonde, a Pour une étude comparée de la littérature québécoise et des littératures coloniales américaines ", Journal of Canadian Studies/ Revue d'études canadiennes, vol. 32, $\mathrm{n}^{\circ} 2,1997, \mathrm{p} .72-78$. 
d'être défriché. Yvan Lamonde et Jean Morency retracent, pour les domaines socio-culturel et historique, d'une part, et littéraire, d'autre part, les enjeux et la portée des notions d'américanité et d'américanisation, en offrant chacun un vaste tableau des recherches effectuées dans ce domaine. Lamonde insiste, dans la perspective historique qu'il adopte, sur l'américanité comme composante majeure de l'identité canadiennefrançaise, en affirmant d'emblée que " s'américaniser, c'est être d'Amérique . Il montre en même temps que la notion même d'américanité a toujours impliqué "une critique sinon un refus d'impérialisme étatsunien", à partir de positions idéologiques parfois très différentes. Morency propose, quant à lui, une distinction fort utile entre l'، américanisation * - généralement associée " à la consommation de la culture * et aux processus d'acculturation et d'imitation réceptifs -, et l'* américanité * désignant justement "le volet positif de l'américanisation * et impliquant ainsi des "influences librement choisies", des "transferts culturels conscients et voulus ", notamment dans les domaines artistique et littéraire. Constatant que ces deux notions, à y regarder de plus près, se recoupent, il propose par la suite d'étudier, aussi bien dans la production de masse (illustrée par la chanteuse country québécoise Renée Martel) que dans la production restreinte (illustrée par les romans de Jacques Poulin et de Victor-Lévy Beaulieu), les "phénomènes de nature interculturelle" qui constituent tant les processus d'américanité que ceux d'américanisation : les influences assumées et reconnues, les usages intertextuels et interdiscursifs, les formes de traduction et d'adaptation, ainsi que les " pratiques de création caractérisées par les emprunts et l'invention de formes hybrides ".

De leur côté, Ute Fendler et Christoph Vatter (Saarbrücken) se penchent sur les avatars intermédiatiques et intertextuels du mythe d'Évangéline au Canada francophone et aux États-Unis, depuis le $\mathrm{XIX}^{\mathrm{e}}$ siècle. En montrant, à travers des exemples significatifs de films, de comédies musicales et de textes littéraires, comment le personnage d'Évangéline a été "repris " et " réanimé avec des objectifs changeants selon les buts et les couleurs idéologiques des auteurs [et] selon les médias utilisés ", cette étude met en même temps en lumière comment les notions d'américanisation et d'américanité s'inscrivent dans l'histoire intermédiatique d'un mythe collectif : les appropriations du mythe par la 
culture de masse états-unienne, en particulier par l'industrie cinématographique hollywoodienne, apparaissent ainsi comme des formes d'américanisation, tandis que les réappropriations, les relectures et déconstructions acadiennes et francophones semblent autant d'expressions d'une américanité librement revendiquée.

Notre étude retrace quant à elle la trajectoire biographique transaméricaine et l'œuvre journalistique et littéraire de Paul-Marc Sauvalle, Français d'origine ayant immigré au Canada en 1884, qui apparaît comme un précurseur de l'américanité contemporaine : à travers, d'abord, son parcours personnel qui l'amena successivement en Louisiane, au Mexique, dans d'autres parties des États-Unis et au Canada, où il devint un des journalistes libéraux de tout premier plan au début du $\mathrm{xx}^{\mathrm{e}}$ siècle; et, ensuite, à travers son rôle d'intermédiaire interculturel, d'a interface " entre les " trois Amériques ", francophone, anglophone et hispanophone, qu'il articula dans de nombreux articles et dans son ouvrage majeur, Louisiane-Mexique - Canada (1891).

Les articles de Beatrice Bagola et de Katrin Mutz s'attachent enfin à la dimension linguistique du phénomène de l'américanisation. Bagola, partant de la place respective de l'anglais et du français sur Internet, analyse la concurrence entre les terminologies anglaise et française en tenant compte également des différences frappantes à l'intérieur de la francophonie, et en particulier entre le Québec et la France. Mutz étudie pour sa part l'impact de l'anglais sur le français en Louisiane. Son étude montre, à partir de nombreuses recherches socio-linguistiques, le recul continu du français par rapport à l'anglais depuis les premières décennies du $\mathrm{xIX}^{e}$ siècle et le caractère "moribond " du français aujourd'hui, malgré les efforts institutionnels. Elle indique aussi que le a processus de décréolisation progressive " mènera probablement "à la mort du créole louisianais :

Poursuivre les questionnements comparatistes et interculturels tracés dans les différents articles de ce dossier constitue certes le défi majeur des recherches futures sur le phénomène de l'américanité et les processus d'américanisation dans les cultures francophones nord-américaines. ll sera nécessaire, à la suite des travaux déjà existants ou en cours dans 
ce domaine ${ }^{19}$, d'élargir le regard comparatiste et d'inclure à cette problématique notamment les sociétés anglophones et hispanophones du continent américain, ainsi que les sociétés européennes, afin de mieux cerner les spécificités et les traits communs de la perception de l'Amérique états-unienne, de l'anti-américanisme et des formes d'appropriation de la culture américaine - états-unienne et autres - dans leur complexité et leur richesse. Les articles du présent dossier tracent des pistes d'exploration dans ce sens, sur le plan tant de la culture littéraire, cinématographique et artistique que de la culture matérielle et de la langue. S'il est vrai, comme l'affirme Gérard Mermet, que "[l]es Français sont porteurs de trois cultures: nationale, régionale, américaine ${ }^{20}$, cela doit être mis en parallèle avec la fameuse formule d'Yvan Lamonde soulignant l'importante composante américaine de l'identité québécoise. Mais, à y regarder de plus près, on verrait apparaître des divergences fondamentales entre l'impact états-unien sur la modernisation du Québec et celui ressenti dans l'Allemagne, l'Italie ou la France de l'après-guerre, qui ont pourtant vécu - il est vrai, avec une intensité moindre - le même type de transferts culturels dans tous les domaines esthétique, architectural, matériel, intellectuel, gastronomique - que les sociétés francophones en Amérique du Nord ${ }^{21}$.

19. Voir notamment les travaux d'Yvan Lamonde, de Gérard Bouchard, de Jean Morency et de Patrick Imbert cités plus haut, ainsi que Donald Cuccioletta, JeanFrançois Côtê, Frédéric Lesemann [éd.], Le grand récit des Amériques. Polyphonie des identités culturelles dans le contexte de la continentalisation, Québec, Éditions de l'IQRC, 2001; Zilá Bernd [éd.], Americanidade e transferências culturais. Porto Alegre, Movimento, 2003; "Transculturalisms/Les transferts culturels *, International Journal of Canadian Studies/Revue internationale d'études canadiennes, vol. 27, printemps 2003 ; Jean Morency, - La (re)découverte de l'Amérique. Le rôle de quelques médiateurs culturels dans le Québec de l'entre-deux-guerres *, dans Jean Morency, Hélène Destrempes, Denise Merkle et Martin Pâquet [éd.], Des cultures en contact. Visions de l'Amérique du Nord francophone, Québec, Nota bene, 2005, p. 299-312.

20. Gérard Mermet, Francoscopie 2003. Pour comprendre les Français, Paris, Larousse, 2002, p. 121.

21. Voir sur cette problématique Olivier Dard et Hans-Jürgen Lüsebrink [éd.], Américanisations et anti-américanismes comparés. Actes du colloque de Metz et de Saarbrücken, décembre 2004, Röhrig Universitätsverlag, 2005 (à paraître), dont les textes concernent l'Allemagne, la France, l'Italie, la Suisse et le Canada. 